\title{
EMPLEO DEL FUROSEMID DURANTE EL EMBARAZO
}

\author{
Dr. Fernando Sánchez Torres*
}

La aparición de edemas durante los últimos meses del embarazo no es un hecho infrecuente. Aunque la retención hidrosalina se ha tenido como un fenómeno casi natural de las embarazadas, un aumento excesivo de peso, acompañado o no de edemas, impone una seria atención por parte del obstetra ya que puede ser el anuncio de que se está iniciando una toxemia gravídica.

Es posible que la disminución del sodio en la alimentación de las embarazadas con edemas sea, en muchos casos, medida suficiente para combatirlos (2). Sin embargo, en consideración a que no siempre esas pacientes cumplen las indicaciones de su médico respecto a la dieta hiposódica, hay tendencia general a prescribir desde un principio sustancias con efecto diurético. Parece razonable que así sea; aún más, algunos aconsejan que se administren diuréticos con fines profilácticos durante el último trimestre a aquellas mujeres en quienes la toxemia suele aparecer con frecuencia (por ejemplo: primigestantes, embarazos múltiples, hipertensión esencial, diabetes, etc.).

Pese a que no está bien aclarado el complejo mecanismo fisiopatológico de la preeclampsia-eclampsia, no hay duda de que la retención hidrosalina juega un papel predominante en su evolución. De ahí que toda medida encaminada a combatirla ha de ser en verdad, base primordial del tratamiento.

En la actualidad el arsenal terapéutico se ha visto enriquecido con el advenimiento de diuréticos cada vez más activos y con menos efectos secundarios. Uno de estos es el "Furosemid" (ácido 4-cloro-N (2-furilmetil) 5-sulfamil-antranílico)**, de bondad diurética ampliamente comprobada en las distintas afecciones que se acompañan con edemas $(3,4,7$, $8)$.

Durante la gestación el Furosemid también ha sido utilizado con éxito en aquellos síndromes edematosos que a veces la complican $(1,5,6,9)$. Para valorar su eficacia en estas circunstancias emprendimos un estudio clínico, cuyos resultados son el motivo de la presente comunicación.

\section{Material y Métodos}

Este estudio fue llevado a cabo en el Servicio de Toxemias del Instituto Materno Infantil, de Bogotá, Colombia, en un grupo de 15 pacientes hospitalizadas por presentar edemas durante el curso de su embarazo. Para precisar la etiología de esos edemas,

* Profesor Asistente del Departamento de Obstetricia y Ginecología de la Universidad Nacional de Colombia.

** Lasix (Laboratorios Hoechst AG). 
cada enferma fue sometida a un cuidadoso estudio clínico y de laboratorio. En dos ocasiones en que el diagnóstico por estos métodos no estaba claro, se practicó biopsia percutánea del riñón. Así fue posible clasificarlas en la siguiente forma: 5 enfermas padecían toxemia gravídica aguda; 5 tenían enfermedad crónica vascular hipertensiva (ECVH) asociada a toxemia; 2 presentaban síndrome nefrótico por glomerulonefritis, uno de ellos asociado a pielonefritis; $y$, finalmente, 3 mujeres tenían edemas de causa indeterminada (edema gravídico).

Para seleccionar estas enfermas fue requisito indispensable que no hubieran recibido previamente ninguna medicación diurética ni que hubieran estado sometidas a dieta hiposalina. Antes de emprender el tratamiento con Furosemid se mantuvieron en completo reposo durante 24 horas, lapso que se aprovechó para observar el volumen de la diuresis espontánea y practicar los siguientes exámenes de laboratorio: cuadro hemático completo, clasificación sanguínea, glicemia, azoemia, creatininemia, proteinemia y parcial de orina. Se investigaron, además, sodio y potasio en sangre $y$ en orina de 24 horas.

Todas las pacientes estuvieron hospitalizadas durante el tiempo de la experiencia y fueron controladas diariamente, a la misma hora y por el mismo médico, anotándose la presión arterial, la temperatura, el peso, el volumen de orina eliminada, el estado fetal y cualquier manifestación subjetiva que aquejaran. La dieta suministrada fue igual para todas, con un contenido aproximado de 5 a 7 gr. de sodio; además, fuera de los líquidos de la alimentación, se permitió la ingestión de agua corriente a voluntad de las pacientes.
A todas se les suministraron 80 mg. de Furosemid al día, repartidos e ndosis de $40 \mathrm{mg}$. cada 12 horas, durante un lapso de ocho días. Al día siguiente de iniciado el tratamiento se volvió a investigar sodio y potasio en sangre y orina de 24 horas, exámenes que se repitieron al finalizar la experiencia. Se procuró no administrar ninguna droga distinta al Furosemid para poder observar su posible efecto antihipertensivo y solo, en contadas ocasiones, utilizamos fenobarbital ante el temor de que pudieran presentarse crisis convulsivas del tipo de la eclampsia.

\section{Resultados}

Para comodidad de la descripción de los resultados, haremos referencia por aparte de cada uno de los grupos de pacientes.

\section{Primer grupo: Pacientes con toxemia gravídica aguda}

De las cinco enfermas con toxemia aguda cuatro eran preeclámpticas y una eclámptica. En ésta el tratamiento con Furosemid se inició 48 horas después de controladas las convulsiones con fenobarbital, sulfato de magnesio y acepromazina.

En el Cuadro No 1 se señalan la edad del embarazo y las modificaciones del peso y la presión arterial. Puede observarse que en todas hubo reducción notable del peso (promedio de 2,1 Kg.). En dos enfermas la presión mínima descendió, en dos no se modificó y en otra aumentó.

En el Cuadro № 2 se aprecian las modificaciones individuales de la diuresis, del sodio y del potasio en plasma y orina, comprobados antes del tratamiento, al día siguiente de iniciado éste y al terminar la observación. Llama la atención que con la dosis empleada no hubo eliminación 


\section{CUADRO NN 1}

\section{PACIENTES CON TOXEMIA AGUDA}

\begin{tabular}{ccccccc}
\hline Caso No. & $\begin{array}{c}\text { Edad del } \\
\text { embarazo }\end{array}$ & Peso inicial & Peso final & P. arterial inicial & P. arterial final \\
\hline 1 & 23 semanas & $65 \mathrm{~kg}$. & $62,5 \mathrm{~kg}$ & $150 / 90$ & $130 / 80$ \\
2 & 32 semanas & $82 \mathrm{~kg}$. & $78 \mathrm{~kg}$. & $150 / 100$ & $130 / 90$ \\
3 & 32 semanas & $56 \mathrm{~kg}$. & $50 \mathrm{~kg}$. & $145 / 95$ & $140 / 95$ \\
4 & 36 semanas & $40,5 \mathrm{~kg}$. & $38,5 \mathrm{~kg}$. & $180 / 120$ & $170 / 140$ \\
\hline
\end{tabular}

masiva de líquidos; el volumen de la diuresis, que en todos los casos era escaso, aumentó notoriamente. En la misma forma, la excreción de sodio en la orina se elevó al día siguiente de iniciado el tratamiento para disminuir, de manera constante, al octavo día. A pesar de haber un aumento de la excreción de potasio por la orina, los niveles plasmáticos se mantuvieron normales.

Dos enfermas cuya toxemia se consideró clínicamente controlada deja- ron el servicio para seguir un tratamiento ambulatorio; las tres restantes tuvieron su parto poco después de finalizada la experiencia (casos Nos. 3, 4 y 5), naciendo los niños vivos y en buenas condiciones. A la paciente que había padecido eclampsia (caso № 5), una vez completados los ocho días de tratamiento con Furosemid, se agregó reserpina y fenobarbital; más tarde dio a luz, espontáneamente, un niño vivo de $1.700 \mathrm{~g}$.

\section{CUADRO N: 2}

PACIENTES CON TOXEMIA AGUDA.

MODIFICACIONES DE LA DIURESIS, SODIO Y POTASIO.

\begin{tabular}{|c|c|c|c|c|c|}
\hline \multirow[b]{2}{*}{ Cascos individuales } & \multirow{2}{*}{$\begin{array}{l}\text { Diuresis en } \\
24 \text { horas }\end{array}$} & \multicolumn{2}{|c|}{ Plasma } & \multicolumn{2}{|c|}{ Orina } \\
\hline & & $\mathrm{Na}$ & $\mathrm{K}$ & $\mathrm{Na}$ & $\mathrm{K}$ \\
\hline \multicolumn{6}{|l|}{ Caso No. 1} \\
\hline Antes del tratamiento & $700 \mathrm{cc}$ & 130 & 5 & 105 & 59 \\
\hline En el primer día & $1.100 \mathrm{cc}$ & 139 & 4,9 & 125 & 75 \\
\hline En el octavo día & $950 \mathrm{cc}$. & 132 & 5 & 120 & 40 \\
\hline \multicolumn{6}{|l|}{ Caso No. 2} \\
\hline Antes del tratamiento & $1.000 \mathrm{cc}$ & 135 & 4,5 & 110 & 36 \\
\hline En el primer día & $1.500 \mathrm{cc}$ & 138 & 4,6 & 145 & 55 \\
\hline En el octavo día & $1.300 \mathrm{cc}$ & 134 & 4,3 & 144 & 86 \\
\hline \multicolumn{6}{|l|}{ Caso No. 3} \\
\hline Antes del tratamiento & $950 \mathrm{cc}$ & 134 & 5,1 & 120 & 39 \\
\hline En el primer día & $1.600 \mathrm{cc}$ & 135 & 6,5 & 126 & 54 \\
\hline En el octavo día & $1.500 \mathrm{cc}$ & 130 & 4,8 & 84 & 52 \\
\hline \multicolumn{6}{|l|}{ Caso No. 4} \\
\hline Antes del tratamiento & $900 \mathrm{cc}$ & 130 & 4,2 & 100 & 32 \\
\hline En el primer d.a & $1.300 \mathrm{cc}$. & 136 & 5 & 157 & 37 \\
\hline En el octavo d.a & $850 \mathrm{cc}$. & 130 & 5,4 & 119 & 66 \\
\hline \multicolumn{6}{|l|}{ Caso No. 5} \\
\hline Antes del tratamiento & $500 \mathrm{cc}$ & 138 & 5,7 & 70 & 69 \\
\hline En el primer día & $1.100 \mathrm{cc}$ & 136 & 5,4 & 90 & 94 \\
\hline En el octavo día & $850 \mathrm{cc}$ & 130 & 5,9 & 82 & 70 \\
\hline
\end{tabular}

NOTA: Na y $K$ en $\mathrm{mEq} / \mathrm{L}$. 


\section{Segundo grupo: Pacientes con ECVH y toxemia agregada}

En este grupo fueron estudiadas cinco mujeres. En el Cuadro № 3 apreciamos que también hubo en todas disminución del peso $(3.1 \mathrm{~kg}$. en promedio ) pero no hubo descenso significativo de la presión arterial. Un feto de 32 semanas de gestación murió in útero durante el tratamiento (caso No 1 ).
En el Cuadro No 4 se advierte que la diuresis fue más intensa en este grupo de pacientes que en aquel con toxemia aguda sola. No se observó depleción de potasio ni efecto secundario alguno.

Completados los ocho días con Furosemid, únicamente se agregó reserpina hasta el momento del parto. Durante este período murió otro feto in útero (caso № 3). Los otros tres niños nacieron vivos, en perfectas condiciones.

\section{CUADRO NN 3}

PACIENTES CON ECVH $Y$ TOXEMIA AGUDA AGREGADA

\begin{tabular}{ccccccc}
\hline Caso No. & $\begin{array}{c}\text { Edad del } \\
\text { embarazo }\end{array}$ & Peso inicial & Peso final & P. arterial inicial & P. arterial fina! \\
\hline 1 & 32 semanas & $70,5 \mathrm{~kg}$. & $64 \mathrm{~kg}$ & $175 / 110$ & $170 / 105$ \\
2 & 36 semanas & $71 \mathrm{~kg}$. & $68 \mathrm{~kg}$ & $180 / 100$ & $150 / 90$ \\
3 & 27 semanas & $65 \mathrm{~kg}$. & $60 \mathrm{~kg}$. & $210 / 130$ & $1700 / 130$ \\
4 & 32 semanas & $57 \mathrm{~kg}$. & 56 & $\mathrm{~kg}$. & $170 / 120$ & $170 / 100$ \\
5 & 36 semanas & $56 \mathrm{~kg}$. & 54 & $\mathrm{~kg}$. & $180 / 105$ & $170 / 110$ \\
\hline
\end{tabular}

CUADRO No 4

MODIFICACIONES DE LA DIURESIS, SODIO Y POTASIO.

\begin{tabular}{|c|c|c|c|c|c|}
\hline \multirow[b]{2}{*}{ Casos individuales } & \multirow{2}{*}{$\begin{array}{l}\text { Diuresis en } \\
24 \text { horas }\end{array}$} & \multicolumn{2}{|c|}{ Plasma } & \multicolumn{2}{|c|}{ Orina } \\
\hline & & $\mathrm{Na}$ & K & $\mathrm{Na}$ & K \\
\hline \multicolumn{6}{|l|}{ Caso No. 1} \\
\hline Antes del tratamiento & $1.100 \mathrm{cc}$. & 136 & 4,5 & 102 & 40 \\
\hline En el primer día & $2.400 \mathrm{cc}$ & 136 & 4,2 & 130 & 19 \\
\hline En el octavo día & $1.600 \mathrm{cc}$ & 136 & 4,5 & 98 & 58 \\
\hline \multicolumn{6}{|l|}{ Caso No. 2} \\
\hline Antes del tratamiento & $1.530 \mathrm{cc}$. & 135 & 4,1 & 95 & 70 \\
\hline En el primer día & $2.650 \mathrm{cc}$ & 138 & 4,5 & 108 & 95 \\
\hline En el octavo día & $1.400 \mathrm{cc}$ & 130 & 5,3 & 102 & 36 \\
\hline \multicolumn{6}{|l|}{ Caso No. 3} \\
\hline Antes del tratamiento & $1.000 \mathrm{cc}$ & 134 & 4,1 & 125 & 21 \\
\hline En el primer día & $2.400 \mathrm{cc}$ & 135 & 4,1 & 165 & 40 \\
\hline En el octavo día & $1.450 \mathrm{cc}$ & 130 & 4,4 & 92 & 22 \\
\hline \multicolumn{6}{|l|}{ Caso No. 4} \\
\hline Antes del tratamiento & $350 \mathrm{cc}$. & 130 & 4 & 112 & 33 \\
\hline En el primer día & $900 \mathrm{cc}$. & 135 & 4,6 & 120 & 35 \\
\hline En el octavo día & $1.100 \mathrm{cc}$ & 131 & 5,1 & 88 & 52 \\
\hline \multicolumn{6}{|l|}{ Caso No. 5} \\
\hline Antes del tratamiento & $1.200 \mathrm{cc}$ & 138 & 3,8 & 91 & 38 \\
\hline En el primer día & $2.420 \mathrm{cc}$ & 132 & 4,2 & 119 & 45 \\
\hline En el octavo día & $1.650 \mathrm{cc}$. & 134 & 4,6 & 102 & 36 \\
\hline
\end{tabular}


Tercer grupo: Pacientes con síndrome nefrótico

Como anotamos atrás, las dos enfermas de este grupo fueron sometidas a biopsia percutánea del riñón para precisar el origen de su padecimiento. En ambas la lesión de fondo correspondía a una glomerulonefritis crónica, en una de ellas asociada a pielonefritis (cuadro № 5, caso № 2 ).
En el Cuadro № 6 apreciamos que la escasa diuresis espontánea se modificó muy poco con el tratamiento; una paciente aumentó $3 \mathrm{~kg}$. de peso en ocho días y presentó convulsiones al séptimo día de estar recibiendo Furosemid (caso № 1). Es necesario anotar que las dos enfermas evolucionaron fatalmente a pesar de haber recibido otros tipos de medicación diurética, tal como se aconseja en estos casos.

\section{CUADRO N: 5}

PACIENTES CON SINDROME NEFROTICO

\begin{tabular}{cccccccc}
\hline Caso No. & $\begin{array}{l}\text { Edad del } \\
\text { embarazo }\end{array}$ & Peso inicial & Peso final & P. arterial inicial & P. arterial final \\
\hline 1 & 23 semanas & $61 \quad \mathrm{~kg}$. & 64 & $\mathrm{~kg}$ & $130 / 90$ & $140 / 95$ \\
2 & 34 semanas & $61,5 \mathrm{~kg}$. & 61 & $\mathrm{~kg}$. & $110 / 80$ & $115 / 80$ \\
\hline
\end{tabular}

\section{CUADRO N: 6}

SINDROME NEFROTICO. MODIFICACIONES DE LA DIURESIS, SODIO Y POTASIO.

\begin{tabular}{lccccc}
\hline Casos individuales & $\begin{array}{c}\text { Diuresis en } \\
\mathbf{2 4} \text { horas }\end{array}$ & $\mathbf{N a}$ & $\mathbf{K}$ & Na & Orina \\
\hline Caso No. 1 dratamiento & & & & & \\
Antes del trata & $250 \mathrm{cc}$. & 136 & 5,8 & 118 & 33 \\
En el primer día & $500 \mathrm{cc}$. & 132 & 4,5 & 126 & 28 \\
En el octavo día & $350 \mathrm{cc}$. & 134 & 5,1 & 110 & 25 \\
Caso No. 2 del tratamiento & $300 \mathrm{cc}$. & 135 & 5,3 & 102 & $\mathbf{4 0}$ \\
Antes del & $520 \mathrm{cc}$. & 134 & 6,5 & 120 & 43 \\
En el primer día & $320 \mathrm{cc}$. & 136 & 6,5 & 126 & $\mathbf{4 6}$ \\
En el octavo día & & &
\end{tabular}

\section{Cuarto grupo: Pacientes con "edema gravídico"}

Incluímos en este grupo a tres gestantes que presentaban edemas sin que hubiera otra causa distinta al mismo embarazo que explicara la retención hidrosalina. En el Cuadro N : 7 puede verse que en ocho días hubo una pérdida de peso de $4.5,3$ y $5 \mathrm{~kg}$. respectivamente (promedio de 4,1 kg.). Una de ellas presentó vómito y pirosis durante el tratamiento (caso № 1). Las tres dieron a luz niños vivos, en buenas condiciones; en una la bolsa de las aguas se había roto de manera prematura (caso № 2).

El Cuadro № 8 muestra claramente el aumento de la diuresis con las primeras dosis del diurético. Como en los grupos anteriores no hubo descenso del potasio sérico. 
CUADRO N 7

PACIENTES CON "EDEMA GRAVIDICO"

\begin{tabular}{ccccccc}
\hline Caso No. & $\begin{array}{c}\text { Edad del } \\
\text { embarazo }\end{array}$ & Peso inicial & Peso final & P. arterial inicial & P. arterial final \\
\hline 1 & 37 semanas & $70 \mathrm{~kg}$. & $65,5 \mathrm{~kg}$ & $120 / 85$ & $115 / 80$ \\
2 & 37 semanas & $70 \mathrm{~kg}$. & $67 \mathrm{~kg}$. & $130 / 75$ & $130 / 80$ \\
3 & 36 semanas & $80,5 \mathrm{~kg}$. & $75,5 \mathrm{~kg}$. & $135 / 80$ & $120 / 75$ \\
\hline
\end{tabular}

CUADRO N: 8

MODIFICACIONES DE LA DIURESIS, SODIO Y POTASIO.

\begin{tabular}{|c|c|c|c|c|c|}
\hline \multirow[b]{2}{*}{ Casos individuales } & \multirow{2}{*}{$\begin{array}{l}\text { Diuresis en } \\
24 \text { horas }\end{array}$} & \multicolumn{2}{|c|}{ Plasma } & \multicolumn{2}{|c|}{ Orina } \\
\hline & & $\mathrm{Na}$ & $\mathbf{K}$ & $\mathrm{Na}$ & K \\
\hline \multicolumn{6}{|l|}{ Caso No. 1} \\
\hline Antes del tratamiento & $1.100 \mathrm{cc}$. & 138 & 4,4 & 134 & 63 \\
\hline En el primer día & $2.300 \mathrm{cc}$ & 140 & 4,1 & 162 & 70 \\
\hline En el octavo día & $1.400 \mathrm{cc}$ & 134 & 4,5 & 130 & 58 \\
\hline \multicolumn{6}{|l|}{ Caso No. 2} \\
\hline Antes del tratamiento & $800 \mathrm{cc}$ & 134 & 4,2 & 105 & 45 \\
\hline En el primer día & $1.200 \mathrm{cc}$. & 134 & 4,9 & 136 & 72 \\
\hline En el octavo día & $1.900 \mathrm{cc}$. & 132 & 4,3 & 126 & 31 \\
\hline \multicolumn{6}{|l|}{ Caso No. 3} \\
\hline Antes del tratamiento & $1.500 \mathrm{cc}$ & 135 & 4,1 & 93 & 28 \\
\hline En el primer día & $3.300 \mathrm{cc}$. & 136 & 4,5 & 145 & 42 \\
\hline En el octavo día & $2.650 \mathrm{cc}$. & 134 & 4,3 & 100 & 40 \\
\hline
\end{tabular}

\section{Comentario y Conclusiones}

Aunque el número de pacientes estudiadas por nosotros es relativamente pequeño, es posible, en base a los resultados obtenidos, formarnos un concepto acerca del valor terapéutico del Furosemid en aquellos casos de pacientes embarazadas con edemas de distinta etiología.

Importa tener en cuenta para juzgar esos resultados, que nosotros usamos un sistema terapéutico uniforme -independiente de la severidad de los edemas y de la enfermedad de fondo-, administrando 80 mg. de la droga en el curso de 24 horas, repartidos en dos dosis de 40 mg. cada 12 horas. Parece, según otros informes (10), que el efecto diurético del Furosemid es más intenso si se administran los $80 \mathrm{mg}$. de una sola vez, y más aún si se utiliza la vía parenteral. Sabemos que cuando se usan agentes diuréticos por vía oral, su acción puede verse entorpecida por defectos de absorción, particularmente en aquellos enfermos con anasarca, como suelen ser los nefróticos.

Valorando los resultados de cada uno de los grupos estudiados podemos deducir que, excepción hecha de las enfermas con síndrome nefrótico, el Furosemid a la dosis utilizada por nosotros se mostró como un buen elemento terapéutico para combatir la retención hidrosalina durante la gestación; la prueba de ello fue el aumento de la diuresis y de la excreción de sodio con la consecuente disminución de peso. En cambio, no observamos acción favorable como agente antihipertensivo. 
Los efectos colaterales fueron casi nulos; una sola paciente aquejó molestias digestivas, imputables a la droga. No apreciamos acción nociva sobre el curso del embarazo ni sobre el estado fetal. En los dos casos en que el feto falleció in útero la acción del diurético no parece haber tenido ninguna influencia. Es de todos conocido que la muerte fetal en las mujeres con síndromes vasculares hipertensivos es una complicación muy frecuente y casi siempre inevitable.

\section{BIBLIOGRAFIA}

1 DE CECCO, L. Min Medica. 56: 1586, 1965.
2 DIECKMANN, W. J. Y KRAMER, S. Am. J. Obst. \& Gynec. 41: 1, 1941.

3 FRANKE, H.: Dtsch. Med. Wschr. 88: 1695, 1963.

4 KIESSLING, J. Münchener Med. Woch. 2 : 95, 1965.

5 PULLE, C. Min. Medica. 56: 1622, 1965.

6 RATNAM, S. S. Bull. of Kandang Kerban Hosp. 5: 52, 1966.

7 ROBSON, W. Lancet. 2: 1088, 1964.

8 STOKES, W. y NUNN, L. C. Brit. Med. J. 2: $910,1964$.

9 TONNELIER, E. G., CASTRO, E. y DE OTE RO, E. La Semana Médica. 129: 1156, 1966.

10 VORBurger, C. Rev. Med. Sisse Rom. 84: $1,1964$. 